\title{
Diffusion Weighted Imaging (DWI) at 3 Tesla MRI to Evaluate the Tumor Response of the Prostate Carcinoma after Radiation or Antiandrogen Therapy
}

\author{
J. Thiele* and J. Scheibe
}

Department of Diagnostic and Interventional Radiology, St. George Hospital, Leipzig, Germany

Received: October 24, 2013; Accepted: December 10, 2013; Published: December 16, 2013

*Corresponding author: J. Thiele, Department of Diagnostic and Interventional Radiology, St. George Hospital, Leipzig, 04129, Germany, E-mail: Jens. Thiele@sanktgeorg.de

\section{Purpose}

The non-surgical treatment of the prostate carcinoma (PC) exist an increased acceptance of the patients. Prerequisite is however an appropriate monitoring as well as the possibility of the restaging (response). To date the inspection results after primary irradiation through the determination of the PSA-NADIR ("Nadir", arabic = base point, deepest PSA value after therapy). After the ASTRO criteria, a recurrent tumor growth exist if a PSA increase of $<1.5 \mathrm{ng} / \mathrm{ml}$ is detectable. The so-called Bounce phenomenon and the recurrent inflammatory reaction of the prostate tissue demarcate frequently the exact biochemical estimation of the PSA value. After the first hormone therapy of the recidivating prostate carcinoma, presently yet no exact PSA value is determined as a guideline.

\section{Methods and Materials}

We examined 8 patients (4/4) before and after radiation therapy or anti-androgen therapy (after 9-12 month). We used a high field MRT ( 3 Tesla, Magnetom TIM TRIO, SIEMENS Medical, Germany) in the context with a body matrix coil. The multiparametric MRI (mpMRI) includes TSE T2w (TR/ TE $/$ flip angle $=4000 / 125 / 120^{\circ}$, slice thickness $4 \mathrm{~mm}$ ), GEEPI DWI transverse (ADC MAP, b=200,400,800),1H-3DCSIspectroscopy (TR/TE $=750 / 145,8$ acq, $0.4 \mathrm{~cm}^{3}$ voxel), flash-3D $\mathrm{T} 1 \mathrm{w}$ transverse (DCE, dynamic contrast enhancement, TR/TE = $8.61 / 3.33$, flip angle $=12^{\circ}$, slice thickness $3 \mathrm{~mm}, 0$ to $6 \mathrm{~min}, 4 \mathrm{sec} /$ Acq, 7,5 ml Gadovist ${ }^{\circledR}$, Bayer Healthcare, $5 \mathrm{ml} / \mathrm{sec}$, mean curve analysis), TSE T1w fat suppresed transverse (TR/TE/flip angle $=550 / 9 / 40^{\circ}$,slice thickness $5 \mathrm{~mm}$, late contrast enhancement). This standardized measurement is carried out in the Dept. of Radiology of the St. George Hospital, Leipzig for 5 years and it was applied within 1500 patients. The analysis of the ADC value, the signal intensity of the T2-weighted imaging and the slope of the DCE SI curve were requisitioned to judgment of the tumor response.

\section{Results}

All 8 patients showed a volume reduction after the radiation therapy and anti-androgen therapy (mean $38.3 \mathrm{ml} \pm 7.6 \mathrm{ml}$ to $32.4 \mathrm{ml} \pm 6.1 \mathrm{ml}$ ). Decisively the amending of the ADC value (DWI) within the tumor (linear, $b=200 / b=800$ ), that was increased at the 4 patients after radiation therapy from mean $0.87 \times 10^{-3} \mathrm{~mm}^{2} / \mathrm{s} \pm$ 0.21 to $1.23 \times 10^{-3} \mathrm{~mm}^{2} / \mathrm{s} \pm 0.30$. Patients under antiandrogenic therapy $(n=4)$ showed no significant improvement of the ADC value $\left(0.91 \times 10^{-3} \mathrm{~mm}^{2} / \mathrm{s}\right.$ to $1.02 \times 10^{-3} \mathrm{~mm}^{2} / \mathrm{s}$ ) (Figure 3 and 4). The disguising of the hypointense tumor lesion in $\mathrm{T} 2 \mathrm{w}$ was certain in the group of the radiation therapy based on the signal reduction of the gland in the outer zone (Figure 1 and 2 ). The peak enhancement of the curve in the DCE MRI 1 year after treatment in both groups was not significantly changed.

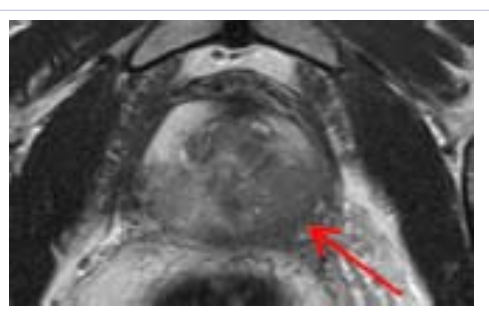

Figure 1: MRI, prostate, TSE T2w, transverse. Hypointense prostate carcinoma, left, dorsal (arrow), before radiotherapy.

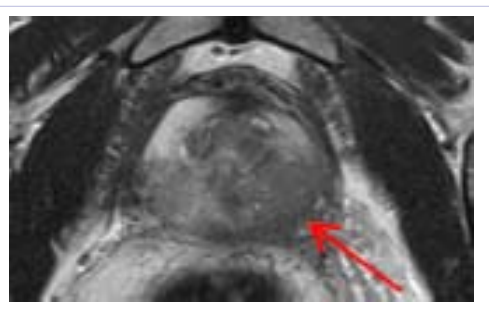

Figure 2: MRI, prostate, TSE T2w, transverse. Middle-intense prostate carcinoma, left, dorsal, 12 month after radiotherapy. Nearly invisible tumor in the outer zone (arow). 


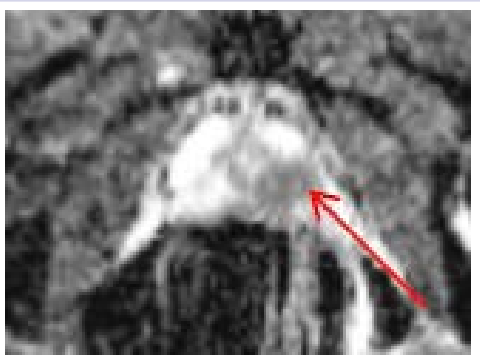

Figure 3: MRI, prostate, DWI (ADC MAP), tumor left dorsal (arrow), ADC value $0.88 \times 10-3 \mathrm{~mm} 2 / \mathrm{s}$, before radiotherapy.

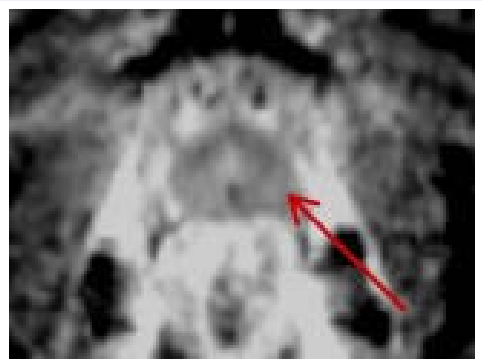

Figure 4: MRI, prostate, DWI (ADC MAP), tumor left dorsal (arrow), ADC value 1.32 x 10-3 mm2/s, 12 month after radiotherapy.

The flattening of the initial enhancement slop of the signal curve (mean 15.3\% $\pm 13.4 \%$ / 10.5\% $\pm 9.1 \%$ ) was comparable in both groups. The curve is by the therapy (radiotherapy and antiandrogenic therapy) in the individual patient changed in different ways. The variable reactions of the endothelial cells, the local different influences on the micro vascularisation and the intra and extra vascular replacement of the Gadolinium in the tumor tissue are responsible for ensuring. In the spectroscopic analysis was shown after 1 year of treatment in both groups a marked metabolic insufficiency of the prostate, such that the ratio between Citrate and Choline were diagnostically not usable.

\section{Conclusion}

The response of a prostate carcinoma can be judged by multi parametric analysis in the mpMRT (3 Tesla). Leading parameter is the variation of the diffusion weighting imaging (increase of the ADC value). The dynamic contrast examination (DCE MRI) seems too inexact for the estimation of the vascularisation of the tumor because an appropriate vessel-model of the prostate is missing. A variable volume reduction through both therapies was to be expected. This is not surprising at first. The uses of the Phoenix Criteria for prevention of recurrence of prostate MRI are complemented by the multiparametric MRI (mpMRI) in clinical practice. The European Association of Urology (EAU) declares that MRI may help from a PSA value of 1-2 $\mathrm{ng} / \mathrm{ml}$ to detect a further relapse of tumor growing. The observation of the therapy of prostate carcinoma under application of the local transcutaneous radiotherapy as well as the anti-androgenic therapy opens a new perspective on these treatments. If positive effects are immediately shown in the illustration of these therapies, is also the acceptance of the patients improved significantly. PSA value and DWI (ADC value) are quite capable of the positive effects of local and systemic, not surgical therapy. With the high-field MRI ( 3 Tesla) can the prostate without endorectal coil be examined. Thereby the acceptance is improved by the patient. Further studies on the changes of the tissue structure and functional parameters of the prostate cancer in MRI have to validate these initial results.

\section{References}

1. Weidner, A. M., Dinter, D. J., Bohrer, M., Sertdemir, M., Hausmann, D., Wenz, F., et al. (2012). Multiparametrische MRT der Prostata zum Therapiemonitoring nach Strahlentherapie. Der Radiologe, 52(3), 235-242.

2. Kim, Y., Hsu, I. C., Lessard, E., Kurhanewicz, J., Noworolski, S. M., Pouliot, J. (2008) Class solution in inverse planned HDR prostate brachytherapy for dose escalation of DIL defined by combined MRI/ MRSI. Radiother Oncol, 88(1), 148-155.

3. Kara, T., Akata, D., Akyol, F., Karçaaltıncaba, M., Özmen, M. (2011). The value of dynamic contrast-enhanced MRI in the detection of recurrent prostate cancer after external beam radiotherapy: correlation with transrectal ultrasound and pathological findings. Diagn Interv Radiol, 17(1), 38-43.

4. Pucar, D., Shukla-Dave, A., Hricak, H., Moskowitz, C. S., Kuroiwa, K., Olgac, S., et al. (2005) Prostate cancer: correlation of MR imaging and MR spectroscopy with pathologic findings after radiation therapy initial experience. Radiology, 236(2), 545-553.

5. Woodfield, C. A., Tung, G. A., Grand, D. J., Pezzullo, J. A., Machan, J. T., Renzulli, J. F. (2010). Diffusion-weighted MRI of peripheral zone prostate cancer: comparison of tumor apparent diffusion coefficient with Gleason score and percentage of tumor on core biopsy. AJR Am J Roentgenol, 194(4), 316-322. 